\title{
Detection and maintenance platform For Radar operation unit Based on PC104
}

\author{
Zhonghua Zhang, Xiaozhuang Gao, Dapeng Wang, Ajian Zhang \\ Fire Adjustment Radar, Faculty of Ordnance, Military School of Wuhan \\ Wuhan, China \\ 362493371@qq.com, xiaozhuang@163.com, dapeng@163.com, ajian@qq.com
}

Keywords: PC104; Operation unit; Detection and maintenance platform

\begin{abstract}
This paper introduced a method of designing radar control unit detection and maintenance platform based on PC104, and focused on expounding design of hardware and software of the platform. The platform uses a high-performance PC104 embedded computer as the control core. Realizing state control and detection data exchange through ISA bus and dual port memory interface bus. External equipment includes a control panel and 68-core detection panel. The platform can effectively serve the teaching of Radar test equipment and the detection and maintenance for the operation unit.
\end{abstract}

\section{Introduction}

As one of three units of a type of radar, the control unit is the information processing and control center of the entire radar station, it is also the key equipment for target detection, identification, tracking deviation measurement and secondary display processing of radar target echo signal from the receiving system. It can also carry out joint operations with the fire command system using information machine after the data of target and burst point through information processing and computing.

The unit consists of a host computer subsystem, signal processing subsystem, terminal display subsystem, special keyboard, panel controls, secondary power supply $(+5 \mathrm{~V},+12 \mathrm{~V},-12 \mathrm{~V},+200 \mathrm{~V})$, power control and protection circuit serial I/O communication interface equipment.

The host computer can schedule and manage the internal and external units of other subsystems and functional modules work together coordinately in the way of centralized control through the I/O control port distributing in each system module. The host computer 80186 is also equipped with the main-control software of radar.

The working process of the control unit is entirely controlled by the master computer board inside and the main-control software. During normal operation, through the control panel and dedicated keyboard, you can adjust the operation of radar control and operating parameters of the six working condition, as well as interactive data input, stapling, selecting and other operations.

With the development of computer information technology and integration of electronic technology,the information and digital level of the operation of radar equipment is growing complex, signal processing, terminal control and fault detecting techniques are escalating, the degree of integration continues to improve, so, it puts forward higher requirements to the radar staff for operational capabilities of information technology and maintenance skills. Therefore, we are badly in need of training the professional personnel who has better electronic information infrastructure, higher professional knowledge accomplishment, stronger hands-on ability, higher equipment maintenance skills, and is able to adapt new trends of support of radar equipment under the information, digitization and integration. However, teaching units have less radar equipment subjecting to various conditions. Currently, each teaching unit and institution has more levels and heavier task of training,it makes the problem of radar equipment can not meet the normal teaching increasingly prominent. For this reason,research and develop radar control unit detection and maintenance platform as a training simulator, with the radar mounting teaching, can effectively enrich teaching methods, relief the contradiction of more students, less equipment adequately, 
increase the students' practical machine hours to a certain extent, improve teaching efficiency and strengthen students' professional skills.

PC104 is an embedded computer platform, which is compatible with PC , has flexible scalability, and whose small size, powerful features is ideal for embedded system applications [1-2]. The radar operation unit detection and maintenance platform as a training simulator of terminal handling equipment, has large quantity of signal operation and complex algorithm, requires high-speed , accurate, reliable, and needs an embedded platform with powerful ability of processing.PC104 happens to meet this requirement.

\section{The overall architecture of platform}

A. Hardware components

This paper describes the overall framework design of radar control unit detection and maintenance platform from the hardware components, software designing and other aspects.

The radar operation unit detection and maintenance platform consists of the master unit combination, 68-core detection panel, mouse, keyboard and main control unit 19-core test cable boxes. Hardware block diagram is shown in Figure 1.

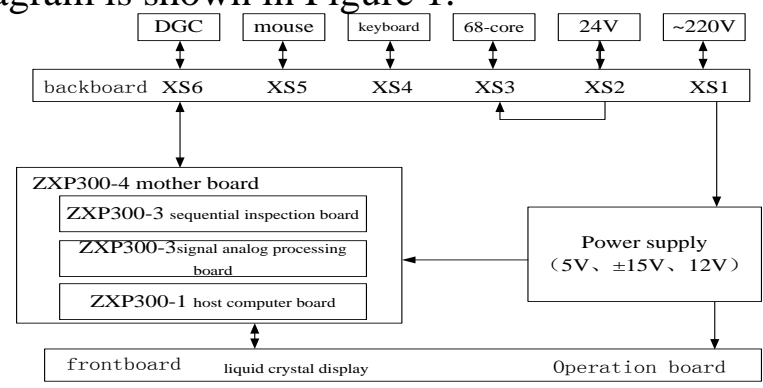

Figure 1. Block diagram of the hardware platform

The functional module of the unit include host computer board, sequential inspection board and signal analog processing board ${ }^{[7-8]}$. The external equipment consists of operating panel,68-core detection panel and liquid crystal display.

The control core of this unit is a kind of high-performance embedded computer board PC104 which has an independent AC-DC power supply module. Realizing state control and detection data exchange of the host computer board, sequential inspection board and signal analog processing board through ISA bus and dual port memory interface bus. It can realize the collection, analysis, filtering and calculations of the detecting point of radar main control unit, the final display of working parameters and status by the software based on WINDOWS operating system. Then it is also responsible for collecting BITE information of the RF unit and the orientation control unit.

The operating panel consists of a platform switch, power indicator light, the high-frequency signal test interface. The 68-core test panel which features 68 brass test connectors correlates directly with the 68-core socket.

\section{B. Function}

The host computer board whose central processing component is the PC104 is the control core of the platform. The control software is running on the host computer, the exchange of real-time data is running on the slave computer by the way of Master-slave control mode. It also completes the real-time control to radar operation unit and the interaction with the radar operator.

The sequential inspection board is the timing control module of platform, its main features include: the oscillator generates a clock signal whose frequency is $14.989 \mathrm{MHz}$.After filtering and amplifying, generates various clock signals required by the other functional modules through frequency dividing circuit. It completes real-time data exchange with the host computer by dual-port memory and single chip microcomputer. It can also monitor the output power by using single chip microcomputer and A/D converter, when the voltage or current signals deviate from the 
nominal value of more than $\pm 10 \%$,it display power failure through the display and indicators in order to achieve the power management for operation unit [3].

The signal analog processing board is signal generation module of the platform. Under the control of PC104, it can complete data exchange with the host computer board through a parallel interface. It completes serial communication with the operation unit by 51 single chip microcomputer and MD8274. According to the control command of the operation unit and the characteristics of the target from the host computer board, it can generate Doppler $\Sigma / \Delta$ video signal of the target, at the same time, it has the function of BITE.

The $14.989 \mathrm{MHz}$ clock signal and $\Sigma / \Delta$ video signal can be detected on the high-frequency test interface of control pane. The 68-core connector can test all kinds of signals from the operation unit.

C. Software Development and Design

The overall software design idea of the platform is the slave computer working in the way of black-box mode. The use of modular design, can simplify function, and also reduce dependence on the host computer, at the same time enhance the reliability of the system ${ }^{[4]}$.Using WinXPE embedded operating system as a development environment, by Target Designer , Component Database Manager and other WinXPE development tools, we complete the custom development for the system software of radar control unit detection and maintenance platform, which has the function of fast start, enhanced write-protected and friendly interface.

\section{Performance Testing}

After development and stereotype of the radar operation unit detection and maintenance platform, this paper tests 5 kinds of power signals and 10 kinds of the main signal from signal function modules differently, the test results are shown in Table 1 and Table 2.

TABLE I THE TEST RESULTS OF THE POWER MODULES

\begin{tabular}{|c|c|c|c|}
\hline Test items & Indicator & $\begin{array}{c}\text { Measured } \mathbf{v} \\
\text { alue }\end{array}$ & Conclusion \\
\hline \multirow{4}{*}{ Output } & $24 \mathrm{~V} \pm 1 \mathrm{~V}$ & $24.09 \mathrm{~V}$ & Meet the requirements \\
\cline { 2 - 4 } & $5 \mathrm{~V} \pm 0.5 \mathrm{~V}$ & $5.12 \mathrm{~V}$ & Meet the requirements \\
\cline { 2 - 4 } & $15 \mathrm{~V} \pm 1 \mathrm{~V}$ & $14.98 \mathrm{~V}$ & Meet the requirements \\
\cline { 2 - 4 } & $-15 \mathrm{~V} \pm 1 \mathrm{~V}$ & $-14.86 \mathrm{~V}$ & Meet the requirements \\
\cline { 2 - 4 } & $12 \mathrm{~V} \pm 1 \mathrm{~V}$ & $12.57 \mathrm{~V}$ & Meet the requirements \\
\hline
\end{tabular}

TABLE II THE TEST RESULTS OF THE SIGNAL MODULES

\begin{tabular}{|c|c|c|c|c|}
\hline Test items & Indicator & $\begin{array}{l}\text { Measured } \\
\text { value }\end{array}$ & Conclusion & Remark \\
\hline \multirow{2}{*}{ Communication check } & $\begin{array}{c}\text { Host computer board } \\
\text { communication error } \\
\text { rate }<10-6\end{array}$ & 0 & $\begin{array}{l}\text { Meet the } \\
\text { requirements }\end{array}$ & $\begin{array}{l}\text { 80000cycle } \\
\text { check }\end{array}$ \\
\hline & $\begin{array}{l}\text { Sequential inspection } \\
\text { board error rate } \\
<10-6\end{array}$ & 0 & $\begin{array}{l}\text { Meet the } \\
\text { requirements }\end{array}$ & $\begin{array}{c}\text { 80000cycle } \\
\text { check }\end{array}$ \\
\hline $\begin{array}{c}\text { 15MHzReference } \\
\text { clock }\end{array}$ & $\begin{array}{c}14.989 \mathrm{MHz} \pm \\
0.5 \mathrm{MHz}\end{array}$ & $14.989 \mathrm{MHz}$ & $\begin{array}{c}\text { Meet the } \\
\text { requirements }\end{array}$ & - \\
\hline \multirow{2}{*}{ PRF } & $3.66 \mathrm{kHz} \pm 0.2 \mathrm{kHz}$ & $3.645 \mathrm{kHz}$ & $\begin{array}{c}\text { Meet the } \\
\text { requirements }\end{array}$ & - \\
\hline & $2.44 \mathrm{kHz} \pm 0.2 \mathrm{kHz}$ & $2.467 \mathrm{kHz}$ & $\begin{array}{c}\text { Meet the } \\
\text { requirements }\end{array}$ & - \\
\hline $\begin{array}{c}\text { Synchronous clock } \\
\text { signal }\end{array}$ & $58.55 \mathrm{kHz} \pm 0.5 \mathrm{kHz}$ & $58.75 \mathrm{kHz}$ & $\begin{array}{l}\text { Meet the } \\
\text { requirements }\end{array}$ & - \\
\hline \multirow{2}{*}{$\begin{array}{c}\Sigma / \Delta \text { signal test } \\
\text { (before PRF) }\end{array}$} & $10 \mu \mathrm{s} \pm 1 \mu \mathrm{s}$ & $10.89 \mu \mathrm{s}$ & $\begin{array}{c}\text { Meet the } \\
\text { requirements }\end{array}$ & \multirow{2}{*}{$\begin{array}{c}\text { Distance } \\
\text { Setting } \\
\text { 1500m } 0.5 \\
\text { Level }\end{array}$} \\
\hline & $70 \mu \mathrm{s} \pm 5 \mu \mathrm{s}$ & $71.2 \mu \mathrm{s}$ & $\begin{array}{c}\text { Meet the } \\
\text { requirements }\end{array}$ & \\
\hline \multirow{2}{*}{$\begin{array}{c}\Sigma / \Delta \text { signal test } \\
(\text { after } P R F)\end{array}$} & $10 \mu \mathrm{s} \pm 1 \mu \mathrm{s}$ & $10.34 \mu \mathrm{s}$ & $\begin{array}{c}\text { Meet the } \\
\text { requirements }\end{array}$ & \multirow{2}{*}{$\begin{array}{c}\text { Distance } \\
\text { Setting } \\
\text { 1500m } 0.5 \\
\text { Level }\end{array}$} \\
\hline & $70 \mu \mathrm{s} \pm 5 \mu \mathrm{s}$ & $71.6 \mu \mathrm{s}$ & $\begin{array}{c}\text { Meet the } \\
\text { requirements }\end{array}$ & \\
\hline
\end{tabular}


The test results in Table 1 and Table 2 show that, the main indicators of power modules and signal modules of the platform are in line with the requirements. ${ }^{[5-6]}$; After connecting the platform and the radar operation unit, the hand wheel and keyboard response and the function of various working conditions are normal, stable, all of this achieve the desired effect.

\section{Features}

The control core of this unit is a kind of high-performance embedded computer board PC104, which has abundant hardware resources, support for multi-tasking and WinXPE embedded real-time operating system and has the characteristics of fast speed, high precision, powerful function. It can run sophisticated radar signal processing algorithms effectively. It not only improve the speed and accuracy of data transmission, but also simplify the system structure, reduce the number of connections and improve the reliability of the system at the same time by using a combination of Master-slave control and multi-computer control mode from a total bus distributed control technology. It achieves a higher level of integration which can not only ensure real-time and reliability, but also reduce the system power consumption effectively and costs through an integrated power control technology with the use of FPGA, CPLD, and other advanced electronic components together.

\section{Conclusion}

Operations show that the radar operation unit detection and maintenance platform. Firstly, as a training simulator, it can carry out the training of switching, calibration, operating of various working conditions and testing and repairing without the whole machine,can be able to serve the operational practice of machine use and maintenance training courses, can also be content presentations for professional theory courses, enrich teaching methods, innovative teaching mode. It also provides a new way to increase students' hands-on time, improve the skill level. Secondly, the platform realizes the detection to the radar signal and the main technical performance of the operation unit by using a high-performance digital circuits and efficient BITE software, which is combined with sound external devices. The test items are covered by the voltage and high-frequency signal of all the functional circuit in the operation unit. The platform can be used for testing and maintenance of the radar operation unit because of rapid and accurate fault location, the low false alarm rate. In the third place, it established a platform for circuit simulation model of a whole radar system-wide operation control unit,which can implement the radar system technology of signal processing, video processing and terminal control fully. It can help teachers to carry out radar signal detection theory and demonstration. The rationality and practicality of the platform are proved by the using in teaching and practical training.

\section{References}

[1] Wang Shaoli, Lv Chao. Application of PC104 embedded computer [J]. Application of technology of photoelectric,2003,73 (5):30-32.

[2] Ba ning, Zhou Jingjing, Zhang Fan. Research and application of the teaching method for radar based on the integrated machine, and radar equipment[J]. Value engineering,2012(4):213.

[3] Ding Zegang, Gao Yangte. The building of innovative experimental teaching platform of SAR orbit[J]. Experimental technology and management,2011,28(2):68-71.

[4] Lin Maoyong, Ke Youan. The radar signal theory [M]. Beijing:National Defence Industry Press:1984.

[5] In Lu, Liu water, Wang Sichen. The application of virtual simulation technology and its application in the aviation electronic equipment in Teaching [J]. Science and technology information,2008(21):373. 
[6] Ding Zegang, Liu Haibo. The building of new system radar teaching experiment platform [J]. Experimental technology and management,2012,29(1):59-61.

[7] Ren lixiang,Long Teng,Yuan Haipeng. HPRF pulse Doppler stepped frequency radar signal processing and parameter designing[J]. Chinese Journal of Electronics,2007(9):1630-1636.

[8] Li Dayou. Microcomputer interface technology [M]. Beijing: Tsinghua University press,1992.

[9] Mao erke,Long Teng,Han Yueqiu. Digital signal processing of stepped frequency radar [J]. Chinese Journal of Aeronautics,2000(6):16-25.

[10] Ding Lufei, Geng Fulu. The principle of radar [M] (Revised edition). Xi'an:Xi'an Electronic and Science University press,1999. 